\title{
Echocardiographic Parameters Predictive of Poor Outcome in Persistent Pulmonary Hypertension of the Newborn (PPHN): Preliminary Results
}

\author{
Sophie Breinig ${ }^{1,2}$ (D) Odile Dicky ${ }^{2,3} \cdot$ Virginie Ehlinger $^{2} \cdot$ Yves Dulac $^{4} \cdot$ Marie-Odile Marcoux $^{1} \cdot$ Catherine Arnaud $^{2,5}$
}

Received: 1 March 2021 / Accepted: 30 June 2021 / Published online: 31 July 2021

(c) The Author(s), under exclusive licence to Springer Science+Business Media, LLC, part of Springer Nature 2021

\begin{abstract}
The aim is to conduct a pilot study to prospectively describe echocardiographic parameters in neonates with pulmonary hypertension ( $\mathrm{PH}$ ) managed according to current recommendations and to identify those parameters that could predict worsening of short-term outcomes. All neonates less than 28 days old with a diagnosis of $\mathrm{PH}$ were prospectively enrolled in a tertiary care center for 1 year. Two echocardiograms were performed by a trained neonatologist. The first echocardiogram was performed at the time of diagnosis, whereas the second was performed just after basic therapeutic optimization. The cohort included 27 neonates. Mean gestational age at birth was 36.1 weeks gestational age (WGA) (SD: 4) and mean birth weight was $2658 \mathrm{~g}$ (SD: 907). Six neonates (22\%) died before day 28, with a median age at death of $48 \mathrm{~h}$ (IQR [33; 89]). Although the first echocardiogram showed no difference, the second highlighted a strong link between the persistence of right-to left-shunt and death $(p=0.002)$. We showed a link between right-to-left shunt and a poor outcome (death or morbidity) after therapeutic optimization among premature and full-term neonates suffering from $\mathrm{PH}$. We recommend repeating echocardiography after basic therapeutic optimization and for prognostic purposes, taking into account only the second examination. Larger cohorts are needed to confirm these results.
\end{abstract}

Keywords Pulmonary hypertension $\cdot$ Newborn $\cdot$ Prognosis $\cdot$ Echocardiography

\section{Background}

Persistent pulmonary hypertension of the newborn (PPHN) is a common disorder in neonatal intensive care units (NICUs), with an incidence of approximately one in 500-1000 births [1] and a significant mortality rate

Sophie Breinig

s.breinig@orange.fr

1 Neonatal and Pediatric Intensive Care Unit, Children's Hospital, 330 Avenue de Grande-Bretagne, Toulouse Cedex 9, France

2 INSERM, UMR 1027, SPHERE Team, Hôpital Paule de Viguier, 330 Avenue de Grande-Bretagne, TSA 70034, Toulouse, France

3 Neonatal Intensive Care Unit, Children's Hospital, 330 Avenue de Grande-Bretagne, Toulouse Cedex 9, France

4 Pediatric Cardiology, Children's Hospital, 330 Avenue de Grande-Bretagne, Toulouse Cedex 9, France

5 Clinical Epidemiology Unit, University Hospital Toulouse, 37 Allées Jules Guesde, 31000 Toulouse, France (generally 10-15\% [2] and from 4 to 33\% depending on the study). It is caused by failure of the pulmonary circulation to dilate at birth [3]. PPHN can be secondary to birth asphyxia, severe lung parenchymal disease such as meconium aspiration syndrome, respiratory distress syndrome in premature infants, transient tachypnea of full-term newborns, or lung hypoplasia with an associated pulmonary vascular hypoplasia (congenital diaphragmatic hernia, oligohydramnios). Risk factors for aggravation are hypoxemia, hypercapnia, pain and acidosis [3]. Right-to-left extrapulmonary shunts (patent ductus arteriosus [PDA] or patent foramen ovale [PFO]) are responsible for deep hypoxemia, a decrease in pulmonary blood flow, insufficient left ventricle preload and circulatory failure. Moreover, acute right ventricle failure can cause circulatory failure due to the increase in afterload. Sometimes, PPHN is related to a rare disease, such as alveolar capillary dysplasia, with a fatal outcome.

Although the diagnosis of PPHN is first evoked in the presence of clinical signs such as respiratory or hemodynamic instability in a characteristic context (such as those mentioned above), it is confirmed by bedside structural 
and functional echocardiography [4] performed by trained neonatal intensivists [5]. Therefore, it is helpful to first rule out any underlying congenital heart defect [6] (such as total anomalous pulmonary venous return or transposition of the great arteries), establish the diagnosis of PPHN, and then assess the hemodynamic status (hypovolemic or obstructive shock). Recent papers by experts such as Storme [3] recommend an acute analysis of extrapulmonary shunts and management similar to that for duct-dependent congenital heart disease for severe PPHN. A few years ago, the use of prostaglandin E1 (PGE1) to maintain PDA and avoid obstructive shock increased, which prompted the study of new cohorts.

However, although these drugs, combined with advances in ventilation and the use of inhaled nitric oxide (iNO) [7], have resulted in a significant decrease in mortality (from $48 \%$ to $10 \%$ in 20 years [2]), PPHN remains a severe pathology, with respiratory, cardiovascular and short- and longterm neurologic morbidity. Because in most instances it is a completely reversible disease, prompt adequate management, including timely referral to tertiary care, can improve the outcome dramatically. No short-term prognostic factors are available to inform families and to determine who requires extracorporeal membrane oxygenation (ECMO), which is critical considering that planning is essential for safe transfer, but only if necessary, and without unnecessary delay. To our knowledge, few studies have investigated the risk factors for poor short-term outcomes. Steurer [7], Razzaq [8] and Nakwan [9] have highlighted the clinical criteria for prognosis. But studies examining echocardiographic predictors are rare and are often retrospective [10-14] or not designed for this purpose, especially older studies, performed before the era of iNO.

\section{Objective}

The aim of this study was to prospectively describe echocardiographic parameters in neonates with PPHN managed according to current recommendations and to determine which of these could predict a decline in short-term outcomes. It is the first step (pilot study) before a large population-based cohort study with 1000 neonates.

\section{Patients and Methods}

\section{Design and Patients}

This prospective cohort study was performed in the NICU of a tertiary university center in Toulouse, France. All neonates less than 28 days old with an obvious clinical and echocardiographic diagnosis of PPHN (respiratory and hemodynamic instability was compulsory, one echocardiographic sign among those usually described [6] was required, as detailed in Table 1) were prospectively enrolled from April 2012 to April 2013. Congenital heart diseases were excluded. Follow-up was carried out until discharge or death, to identify any immediate side effects, comorbidity or death.

In terms of ethical concerns, only consent from the parents for standard care was required because there was no modification of management

\section{Data Collection}

Two echocardiograms were performed by a trained neonatologist. The first echocardiogram was performed at the time of diagnosis of PPHN, and the second was performed just after basic therapeutic optimization, according to the recommendations in force. The echocardiographic parameters that were assessed are summarized in Table 1. In order to increase reproducibility (intra- and inter-observer reproducibility of echocardiograms was 70-93\% [15]) and because of the great lability of the study population, all intensivists were required to be trained in congenital cardiology (to rule out congenital heart disease) and in functional bedside echocardiography (according to the criteria of the American and European echocardiography societies [5]: "advanced level"). A Sonos 4500 (Philips) was used for the procedure. It did not allow for a second blind interpretation of echocardiograms.

Care methods were chosen by the child's doctor. While following current recommendations, we also had to adapt
Table 1 Echocardiographic parameters assessed (the star designates those used to diagnose pulmonary hypertension)

\begin{tabular}{|c|c|}
\hline & Parameters \\
\hline Pressure evaluation & $\begin{array}{l}\text { Tricuspid regurgitation velocity } \\
\text { Tricuspid regurgitation pressure gradient (using Bernoulli's equation) if analyzable* } \\
\text { Semi quantitative estimation of right atrial pressure }\end{array}$ \\
\hline Septal curve & Infra/iso/supra-systemic pulmonary pressure* \\
\hline Size of cavities & $\begin{array}{l}\text { Semi-quantitative estimation of the size of the right ventricle (dilated/not dilated) } \\
\text { Semi-quantitative estimation of the size of the right atrium (dilated/not dilated) }\end{array}$ \\
\hline Shunts & $\begin{array}{l}\text { At atrial level*: left to right, bidirectional, right to left, absent } \\
\text { At patent ductus arteriosus*: left to right, bidirectional, right to left, absent }\end{array}$ \\
\hline
\end{tabular}


treatment to the PPHN etiology (alveolar recruitment strategy for parenchymal lung disease, fluid administration, or inotropic support in the case of septic shock, for example). PGE1 (ProstineR) was used if DA was restrictive or closed. There were no changes in the recommendations and protocols during the study period. Hemodynamic parameters (heart rate, blood pressure, pre- and post-ductal saturation) were noted at the same time for each echography.

\section{Outcomes}

The primary outcome was survival at day 28 . The secondary outcome criterion was morbidity at discharge among surviving babies (predefined as the occurrence of at least one of the following events: duration of mechanical ventilation exceeding 10 days, oxygen requirement on hospital discharge, requirement for chronic systemic pulmonary hypertension medication (sildenafil or treprostinil in continuous subcutaneous perfusion).

\section{Statistical Analysis}

The analysis was performed using Stata version 11.2 statistical software. The study population was first described using numbers $(n)$ and percentages (\%) for categorical variables, and the number of observations $(n)$, minimum (min) and maximum $(\max )$ values, median, and interquartile range (IQR p25-p75) or the mean and the standard deviation (SD) for continuous variables. Hemodynamic parameters during the first echography and echocardiographic parameters before and after therapeutic optimization were compared according to the child's status on day 28 (alive vs. deceased). Fisher's exact tests were used to compare the distribution of categorical variables between the two groups, while the distribution of quantitative variables was compared between groups using Wilcoxon rank-sum tests. A $p$-value $\leq 0.05$ was considered statistically significant.

\section{Results}

The cohort included 27 neonates, who represented $67.5 \%$ of all infants in the unit suffering from PPHN during the same period. Non-inclusion was due to the unavailability of an experienced echocardiographer at the right moment. Children had a median age at diagnosis of zero days (IQR [0-1]). Mean gestational age at birth was 36.1 WGA [weeks gestational age] (SD: 4) and mean birth weight was $2658 \mathrm{~g}$ (SD: 907). Ten infants (37\%) were considered to be premature (born before $37 \mathrm{WGA}$ ). Etiologies included diaphragmatic hernia (8 infants, 29\%), birth asphyxia $(n=6,22 \%$, including two infants with meconium aspiration, 7.4\%), septic shock $(n=4,15 \%)$, transient tachypnea of the newborn $(n=4,15 \%)$, respiratory distress syndrome $(n=3,11 \%)$ and early digestive surgery $(n=2,8 \%)$. Ventilator support (VN500, Dräger) and associated therapeutics are described in Table 2. Six neonates (22\%) died before day 28 with a median age at death of $48 \mathrm{~h}$ (IQR [33; 89]). Four neonates among the survivors (19\%) presented with at least one factor of morbidity.

Hemodynamic parameters collected from the first echocardiography (i.e. before therapeutic optimization) are reported in Table 3, according to survival status at day 28 . Heart rate and the intensity of inotropic support with norepinephrine significantly differed between groups.

Table 4 presents the echocardiographic parameters before and after therapeutic optimization according to survival status on day 28. The first echocardiographic evaluation showed no difference between neonates who were alive and those who were deceased, except for the presence of a dilated right atrium at the start of care, which was more frequent in neonates who would die before day 28 (83\% vs. $33 \%, p=0.043)$.

The second echocardiogram (after a median of $2 \mathrm{~h} \mathrm{[1}$; 5.5]) was performed in five of the six deceased children and 18 of the 21 survivors. When the second echocardiograms could not be performed, it was due to major instability during the examination or unavailability of the machine, with the exception of one child who died before it could be performed. These results (Table 4) showed a link between shunt direction and death before day 28 ( $p$-value $=0.004)$. Among the eight infants with right-to-left DA after therapeutic optimization, five $(62.5 \%)$ died before day 28 , whereas no child with left-to-right DA, regardless of the time of evaluation, died or presented with risk factors of morbidity (Supplemental Table 1). Death could not be predicted with logistic regression, but by recoding shunt direction in two modalities (right-to-left DA or atrial shunt vs. all other modalities), we confirmed these results $(p=0.002)$. Finally, eight infants presented an analyzable tricuspid regurgitation (TR) (with an estimated median systolic pulmonary pressure of

Table 2 Characteristics of the population: ventilator support and treatments

\begin{tabular}{lrr}
\hline Treatments & $n / N$ & $\%$ \\
\hline iNO & $22 / 27$ & 81 \\
HFO & $16 / 27$ & 59 \\
Sedatives & $27 / 27$ & 100 \\
Prone positioning & $4 / 27$ & 15 \\
Inotropic support & $22 / 27$ & 81 \\
Exogenous surfactant & $12 / 27$ & 44 \\
Prostaglandins (PGE1) & $8 / 27$ & 29 \\
\hline
\end{tabular}

$N=27$ (iNO inhaled nitric oxide; $H F O$ high-frequency oscillation: mean pressure ventilation: $13.5 \mathrm{~cm} \mathrm{H} 20$ ) 
Table 3 Hemodynamic parameters registered during the first echography

\begin{tabular}{|c|c|c|c|}
\hline \multirow[t]{3}{*}{ Parameters } & \multicolumn{2}{|c|}{$\begin{array}{l}\text { Survival status at } \\
28 \text { days }\end{array}$} & \multirow{3}{*}{$\begin{array}{l}p \text {-value } \\
\text { (Wilcoxon } \\
\text { rank-sum } \\
\text { test) }\end{array}$} \\
\hline & $\begin{array}{l}\text { Alive } \\
n=21\end{array}$ & $\begin{array}{l}\text { Deceased } \\
n=6\end{array}$ & \\
\hline & $\begin{array}{l}\text { Median } \\
\text { IQR } \\
\text { Min-max }\end{array}$ & $\begin{array}{l}\text { Median } \\
\text { IQR } \\
\text { Min-max }\end{array}$ & \\
\hline Heart rate & $\begin{array}{l}155 \\
140 ; 161 \\
103 ; 191\end{array}$ & $\begin{array}{l}128 \\
119 ; 139 \\
102 ; 152\end{array}$ & 0.014 \\
\hline $\begin{array}{l}\text { Systolic blood pressure } \\
(\mathrm{mmHg})\end{array}$ & $\begin{array}{l}58 \\
51 ; 66 \\
34 ; 88\end{array}$ & $\begin{array}{l}49 \\
48 ; 53 \\
32 ; 64\end{array}$ & 0.096 \\
\hline $\begin{array}{l}\text { Diastolic blood pressure } \\
\quad(\mathrm{mmHg})\end{array}$ & $\begin{array}{l}35 \\
26 ; 45 \\
11 ; 57\end{array}$ & $\begin{array}{l}31 \\
28 ; 48 \\
12 ; 62\end{array}$ & 1.000 \\
\hline Mean blood pressure $(\mathrm{mmHg})$ & $\begin{array}{l}43 \\
32 ; 48 \\
26 ; 69\end{array}$ & $\begin{array}{l}35 \\
32 ; 39 \\
19 ; 53\end{array}$ & 0.231 \\
\hline \multicolumn{4}{|l|}{$\begin{array}{l}\text { Quantitative assessment of ino- } \\
\text { tropic support }(\mu \mathrm{g} / \mathrm{kg} / \mathrm{min})\end{array}$} \\
\hline Dopamine: $n=17$ & $\begin{array}{l}10 \\
0 ; 7.5 \\
0 ; 20\end{array}$ & $\begin{array}{l}7.5 \\
0 ; 10 \\
0 ; 10\end{array}$ & 0.566 \\
\hline Dobutamine: $n=12$ & $\begin{array}{l}0 \\
0 ; 7.5 \\
0 ; 20\end{array}$ & $\begin{array}{l}10 \\
0 ; 10 \\
0 ; 15\end{array}$ & 0.120 \\
\hline Norepinephrine: $n=11$ & $\begin{array}{l}0 \\
0 ; 0.2 \\
0 ; 0.8\end{array}$ & $\begin{array}{l}0.9 \\
0 ; 1.5 \\
0 ; 2\end{array}$ & 0.023 \\
\hline Pre-ductal $\mathrm{SaO}_{2}(n=26)(\%)$ & $\begin{array}{l}96 \\
91 ; 99 \\
73 ; 100\end{array}$ & $\begin{array}{l}96 \\
90 ; 100 \\
70 ; 100\end{array}$ & 0.860 \\
\hline Post-ductal $\mathrm{SaO}_{2}(n=21)(\%)$ & $\begin{array}{l}90 \\
79 ; 99 \\
15 ; 100\end{array}$ & $\begin{array}{l}74 \\
65 ; 82 \\
60 ; 96\end{array}$ & 0.100 \\
\hline
\end{tabular}

$N=27$. Data are presented as median and interquartile range (IQR p25-75), minimum (min), maximum (max). $\mu \mathrm{g} / \mathrm{kg} / \mathrm{min}$ : micrograms of medication per kilogram of body weight per minute; $\mathrm{SaO}_{2}$ : arterial oxygen saturation

$75.00 \mathrm{mmHg}$ ) in the group of children who died before day 28 (compared to $59.29 \mathrm{mmHg}$ in the other group, $p \geq 0.05$ ).

\section{Discussion}

To our knowledge, our results are the first in a prospective study aimed at clearly identifying the predictive factors of outcome. The underlying rationale is the need to anticipate both the management (which can become very aggressive and sometimes requires timely referral to a tertiary care or ECMO center) and the information to give parents for this severe neonatal pathology. Although they only focus on echocardiographic parameters, our data suggest that the aim of the first echography is mainly to rule out an underlying congenital heart defect, and to then establish the diagnosis of PPHN. However, it provides no early relevant prognostic information. We chose to repeat the echocardiography after classic therapeutic optimization. The results showed a link between shunt direction and death before day 28 , especially with right-to-left DA. Although right-to-left DA has been mentioned in the literature as a potential risk factor for a poor outcome, most results remain insufficient: retrospective studies with an old design to prove iNO efficiency [4, $10,16,17]$, or an imprecise design with inaccurate timing of the echocardiography [13], where the exam was performed "in the first 12 hours after admission," which we believe is quite a long time for this severe and scalable disease. In 2015, Malowitz [14] published an interesting paper that also examined right ventricular parameters. The results of that retrospective study are consistent with ours, but the echocardiography was performed "in the first 6 days." We think that in this rapidly scalable disease, early and regular evaluation of the hemodynamic parameters and the echocardiography by the neonatal intensivist is essential so that treatment can be promptly adjusted. For this reason, the median hour of the second echocardiography is sooner here than in other studies and is a positive point, in line with the clinical profile of our population.

Another strength of our study is that it was conducted in real-life conditions and included recent progress in PPHN management: high-performance ventilators, exogenous surfactant, iNO facilitation, PGE1 and inotropic support, especially with noradrenaline [18]. The use of PGE1 in particular to maintain patent DA and avoid obstructive shock has a positive impact on DA. We now know $[3,19]$ that hypoxemia due to right-to-left shunts is not correlated with tissue hypoxia if both right and left ventricular functions are adequate and hemoglobin level is normal for age. Considering that right-to-left shunts are both a necessary condition for ensuring systemic cardiac output and a reflection of the severity of PPHN, it seems important to combine clinical and echocardiographic predictive factors. In more recent retrospective studies, Peterson et al. [12] emphasized the link between outcome and left ventricle size and output, while Mydam [13] reported both types of right-to-left shunts (PDA and $\mathrm{PFO}$ ), right cavity dilatation, a decrease in maximal pulmonary arterial velocity and clinical factors (a SNAPPE II [Score for Neonatal Acute Physiology, Perinatal Extension] score above 43 was associated with a poor outcome).

It would have been interesting to evaluate mean pulmonary arterial pressure as well. This is a relevant reflection of pulmonary output which was chosen by Gournay [20]. Otherwise, we were initially surprised by how few significant TRs there were. Studies on the subject $[21,22]$ are inconsistent with up to $70 \%$ of the TRs which is less than $10 \%$. 
Table 4 Echocardiographic parameters before and after therapeutic optimization according to life status at day 28 (DA ductus arteriosus; $R V$ right ventricle; $R A$ right atrium), Fisher's exact test

\begin{tabular}{|c|c|c|c|c|c|c|}
\hline & \multicolumn{3}{|c|}{ Before therapeutic optimization } & \multicolumn{3}{|c|}{ After therapeutic optimization } \\
\hline & $\begin{array}{l}\text { Alive at day } \\
28(n=21)\end{array}$ & $\begin{array}{l}\text { Deceased before } \\
\text { day } 28(n=6)\end{array}$ & $p$-value & $\begin{array}{l}\text { Alive at day } \\
28(n=18)\end{array}$ & $\begin{array}{l}\text { Deceased before } \\
\text { day } 28(n=5)\end{array}$ & $p$-value \\
\hline & $N(\%)$ & $N(\%)$ & & $N(\%)$ & $N(\%)$ & \\
\hline Septal curve & & & 0.787 & & & 0.837 \\
\hline Infra-systemic & $2(9)$ & $0(0)$ & & $7(39)$ & $1(20)$ & \\
\hline Iso-systemic & $10(48)$ & $2(33)$ & & $6(33)$ & $2(40)$ & \\
\hline Supra-systemic & $9(43)$ & $4(67)$ & & $5(28)$ & $2(40)$ & \\
\hline DA & & & 0.118 & & & 0.004 \\
\hline None & $6(29)$ & $0(0)$ & & $9(50)$ & $0(0)$ & \\
\hline Left to right & $1(5)$ & $0(0)$ & & $5(28)$ & $0(0)$ & \\
\hline Bidirectional & $8(38)$ & $1(17)$ & & $1(5)$ & $0(0)$ & \\
\hline Right to left & $6(28)$ & $5(83)$ & & $3(17)$ & $5(100)$ & \\
\hline Atrial shunt & & & 0.818 & & & 0.046 \\
\hline None & $8(38)$ & $2(33)$ & & $4(22)$ & $2(40)$ & \\
\hline Left to right & $8(38)$ & $2(33)$ & & $10(56)$ & $0(0)$ & \\
\hline Bidirectional & $4(19)$ & $1(17)$ & & $3(17)$ & $1(20)$ & \\
\hline Right to left & $1(5)$ & $1(17)$ & & $1(5)$ & $2(40)$ & \\
\hline Dilated RA & & & 0.043 & & & 0.360 \\
\hline Yes & $7(33)$ & $5(83)$ & & $7(39)$ & $3(60)$ & \\
\hline No & $14(67)$ & $1(17)$ & & $11(61)$ & $2(40)$ & \\
\hline Dilated RV & & & 0.280 & & & 0.360 \\
\hline Yes & $9(43)$ & $4(67)$ & & 7 (39) & $3(60)$ & \\
\hline No & $12(57)$ & $2(33)$ & & $11(61)$ & $2(40)$ & \\
\hline
\end{tabular}

The second echocardiogram could not be performed for four babies (three alive, one deceased)
This is due to transitional circulation. When the DA is wide open, right to left, it can decrease right ventricle afterload and TR disappears. Among other limits of this preliminary study, we acknowledge that the study population was heterogeneous, with extremely preterm (28-34 WGA), near fullterm (34-37 WGA) and full-term infants. There were also congenital diaphragmatic hernias with a specific pulmonary hypertension pathophysiology. Moreover, during the study, which was relatively short, no ECMO was performed for this indication. Finally, there was no TAPSE (tricuspid annular plane systolic excursion) evaluation, because at the time these references for neonates had just been published [23].

\section{Conclusion}

In this prospective study, we showed a link between rightto-left shunts and a poor outcome (death or morbidity) after therapeutic optimization in premature and full-term neonates suffering from PPHN. We recommend repeating echocardiography after basic therapeutic optimization and for prognostic prediction, taking into account only the second examination. This is a pilot study for a scheduled study with a larger cohort to confirm these results, integrate clinical and biological parameters, and guide clinicians in the management of this severe disease.

Supplementary Information The online version contains supplementary material available at https://doi.org/10.1007/s00246-021-02677-z.

\section{Declarations}

Conflict of interest The authors have no conflicts of interest to declare that are relevant to the content of this article.

\section{References}

1. Greenough A, Khetriwal B (2005) Pulmonary hypertension in the newborn. Paediatr Respir Rev 6(2):111-116

2. Cabral JE, Belik J (2013) Persistent pulmonary hypertension of the newborn: recent advances in pathophysiology and treatment. J Pediatr 89:226

3. Storme L, French Congenital Diaphragmatic Hernia Study Group (2013) Pathophysiology of persistent pulmonary of the newborn: impact of the perinatal environment. Arch Cardiovasc Dis 106:169-177

4. Ochikubo CG, Waffarn F, Turbow R, Kanakriyeh M (1997) Echocardiographic evidence of improved hemodynamics during inhaled nitric oxide therapy for persistent pulmonary hypertension of the newborn. Pediatr Cardiol 18(4):282-287 
5. Mertens L, The writing group of the American Society of Echocardiography in collaboration with the European Association of Echocardiography and the Association for European Pediatric Cardiologists (2011) Targeted neonatal echocardiography in the neonatal intensive care unit: practice guidelines and recommendations for training. Eur J Echocardiogr 12:715-736

6. Singh Y, Tissot C (2018) Echocardiographic evaluation of transitional circulation for the neonatologist. Front Pediatr 6:140. https://doi.org/10.3389/fped.2018.00140

7. Steurer MA, Jelliffe-Pawlowski LL, Baer RJ, Partridge JC, Rogers EE, Keller RL (2017) Persistent pulmonary hypertension of the newborn in late preterm and term infants in California. Pediatrics 139(1):e20161165. https://doi.org/10.1542/peds.2016-1165

8. Razzaq A, Iqbal Quddusi A, Nizami N (2013) Risk factors and mortality among newborns with persistent pulmonary hypertension. Pak J Med Sci 29:1099

9. Nakwan N, Nakwan N, Wannaro J (2011) Predicting mortality in infants with persistent pulmonary hypertension of the newborn with the Score for Neonatal Acute Physiology-Version II (SNAPII) in Thai neonates. J Perinat Med 39(3):311-5. https://doi.org/ 10.1515/JPM.2011.011

10. Fraisse A, Geva T, Gaudart J, Wessel DL (2004) Doppler echocardiographic predictors of outcome in newborns with persistent pulmonary hypertension. Cardiol Young 14(3):277-283

11. Gotteiner NL, Harper WR, Godding SS, Berdusis K, Wiley AM, Reynolds M, Benson DW (1997) Echocardiographic prediction of neonatal ECMO outcome. Pediatr Cardiol 18:270-275

12. Peterson A, Deatsman S, Frommelt M, Mussatto K, Frommelt P (2009) Correlation of echocardiographic markers and therapy in persistent pulmonary hypertension of the newborn. Pediatr Cardiol 30:160-165

13. Mydam J, Zidan M, Chouthai N (2015) A comprehensive study of clinical biomarkers, use of inotropic medication and fluid resuscitation in newborns with persistent pulmonary hypertension. Pediatr Cardiol 36(1):233-239. https://doi.org/10.1007/ s00246-014-0992-5

14. Malowitz JR, Forsha DE, Smith PB, Cotten CM, Barker PC, Tatum GH (2015) Right ventricular echocardiographic indices predict poor outcomes in infants with persistent pulmonary hypertension of the newborn. Eur Heart J Cardiovasc Imaging 16(11):1224-1231. https://doi.org/10.1093/ehjci/jev071

15. Chew MS, Poelaert J (2003) Accuracy and repeatability of pediatric cardiac output measurement using Doppler: 20-year review of the literature. Intensive Care Med 29:1889-94

16. The Neonatal Inhaled Nitric Oxide Study Group (1997) Inhaled nitric oxide in full-term and nearly full-term infants with hypoxic respiratory failure. N Engl J Med 336(9):597-604

17. Rozé JC, Storme L, Zupan V, Morville P, Dinh-Xuan AT, Mercier JC (1994) Echocardiographic investigation of inhaled nitric oxide in newborn babies with severe hypoxemia. Lancet 344:303-305

18. Tourneux P, Rakza T, Bouissou A, Krim G, Storme L (2008) Pulmonary circulatory effects of norepinephrine in newborn infants with persistent pulmonary hypertension. J Pediatr 153(3):345349. https://doi.org/10.1016/j.jpeds.2008.03.007

19. Dumas de la Roque E, Storme L, Mauriat P, Bonnet S (2001) Hypertension pulmonaire de l'enfant et du nouveau-né en réanimation: partie I: physiopathologie. Archives de Pédiatrie 18:68-75

20. Gournay V, Cambonie G, Rozé JC (1998) Doppler echocardiographic assessment of pulmonary blood flow in healthy newborns. Acta Paediatr 87:419-423

21. Berger M, Haimowitz A, Van Tosh A, Berdoff RL, Goldberg E (1985) Quantitative assessment of pulmonary hypertension in patients with tricuspid regurgitation using continuous wave Doppler ultrasound. J Am Coll Cardiol 6(2):359-365

22. Skinner JR, Boys RJ, Hunter S, Hey EN (1991) Non-invasive assessment of pulmonary arterial pressure in healthy neonates. Arch Dis Child 66:386-390

23. Koestenberger $M$ et al (2011) Systolic right ventricular function in preterm and term neonates: reference values of the tricuspid annular plane systolic excursion (TAPSE) in 258 patients and calculation of $Z$-score values. Neonatalogy 100:85

Publisher's Note Springer Nature remains neutral with regard to jurisdictional claims in published maps and institutional affiliations. 